\title{
AFLP Markers Linked to Eastern Filbert Blight Resistance from OSU 408.040 Hazelnut
}

\author{
Honglin Chen ${ }^{1}$, Shawn A. Mehlenbacher ${ }^{2}$, and David C. Smith ${ }^{3}$ \\ Department of Horticulture, 4017 Agricultural \& Life Sciences Building, Oregon State University, \\ Corvallis, OR 97331-7304
}

\begin{abstract}
ADDitional INDEX wORDs. Corylus avellana, filbert, Anisogramma anomala, marker-assisted selection
Abstract. Eastern filbert blight (EFB), caused by Anisogramma anomala (Peck) E. Müller, is a devastating disease to european hazelnut (Corylus avellana L.) orchards in the Willamette Valley of Oregon. Selection OSU 408.040 showed no symptoms or signs of the fungus following greenhouse inoculations, and enzyme-linked immunosorbant assays (ELISAs) were negative. Segregation ratios in three progenies indicate that a single dominant gene controls the resistance. A total of 64 amplified fragment length polymorphism (AFLP) primer combinations were screened using three resistant and three susceptible individuals as well as the parents of the cross OSU 245.098 $\times$ OSU 408.040. Primer combinations that showed no more than one recombinant in these six seedlings were investigated in 30 additional seedlings. Markers that showed $<15 \%$ recombination with resistance were amplified in the remaining seedlings of the population. Five AFLP markers linked in coupling to resistance were identified. B2-125 was located on one side of the resistance locus at a distance of 4.1 centimorgans $(\mathrm{cM})$, while $\mathrm{A} 4-265(9.2 \mathrm{cM}), \mathrm{C2}-175(5.9 \mathrm{cM})$ and D8-350 $(2.5 \mathrm{cM})$ were on the other side, and A8-150 cosegregated with resistance. Three of these markers (B2-125, C2-175, and D8-350) were also linked in coupling in a similar order in seedlings from a second progeny. These markers may be useful in marker-assisted selection for eastern filbert blight resistance from hazelnut selection OSU 408.040.
\end{abstract}

Production of the european hazelnut in Oregon's Willamette Valley represents $98 \%$ of the United States production and $3 \%$ to $5 \%$ of the world production, respectively (Food and Agriculture Organization of the United Nations, 2003). However, the Oregon hazelnut industry is threatened by eastern filbert blight (EFB), a disease caused by the pyrenomycete Anisogramma anomala. The fungus causes severe cankers, rapid yield loss, and eventually tree death in 5 to 12 years if control measures are not practiced (Pinkerton et al., 1993). Current control practices include fungicide applications and therapeutic pruning. However, due to the expense of fungicides and the dramatic yield loss caused by severe pruning to remove cankers, genetic resistance is the most desirable and economical means of disease control (Mehlenbacher, 1994). Therefore, developing cultivars resistant to EFB is a major objective of the Oregon State Univ. (OSU) hazelnut breeding program.

Complete resistance to EFB was first discovered in the obsolete pollinizer 'Gasaway' (Cameron, 1976) and is conferred by a single dominant gene (Mehlenbacher et al., 1991). This gene has been the major source of resistance utilized in the OSU breeding program, while the search for new sources of complete resistance has continued. Selection OSU 408.040, grown from seeds labeled "Weschcke hybrid" collected at the research farm of the Univ. of Minnesota in 1987, showed no symptoms or signs of the fungus following greenhouse inoculation in Spring 1995, and enzymelinked immunosorbant assay (ELISA) test results were negative (S. Mehlenbacher, unpublished). Trees inoculated the following year also remained free of the fungus, confirming the resistance.

Received for publication 8 Oct. 2004. Accepted for publication 29 Nov. 2004. A technical paper of the Oregon Agricultural Experiment Station. This research was supported by the Oregon Hazelnut Commission and a Specific Cooperative Agreement with the USDA-ARS. We thank David Bedford and James Luby (Dept. of Horticulture, Univ. of Minnesota) for sending the "Weschcke hybrid" seeds from which OSU 408.040 was selected.

${ }^{1}$ Current address: Graduate Group Complex, 310 Life Sciences Addition, One Shields Avenue, University of California, Davis, CA 95616.

2Professor, to whom reprint requests should be sent; e-mail mehlenbs@science. oregonstate.edu

${ }^{3}$ Senior Research Assistant.
Selection OSU 408.040 phenotypically appears to be pure $C$. avellana, resembling typical wild seedlings in Europe, rather than an interspecific hybrid between $C$. americana Marshall and $C$. avellana from Weschcke's (1954) private nut breeding program. In addition to EFB resistance, OSU 408.040 has desirable early nut maturity, but it is not precocious, is highly susceptible to big bud mite (primarily Phytoptus avellanae Nal.), nut size is small, nut shape is very long, and the kernels do not blanch.

Current methods for evaluation of EFB resistance are slow and expensive. Cankers usually develop and can be observed 16-20 months after initial exposure. A desire to slow disease spread requires isolation of disease tests from commercial orchards and breeding activities. ELISA following greenhouse inoculation shortens the detection time to 6 months (Coyne et al., 1996). However, this process is still time-consuming, and in some cases, yields ambiguous results even with repeated tests. Marker-assisted selection (MAS) provides a means of screening genotypes for EFB resistance at an early stage. Only seedlings with the appropriate markers are planted in the field and evaluated for other traits. Random amplified polymorphic DNA (RAPD) markers tightly linked to the 'Gasaway' resistance gene have been identified (Davis and Mehlenbacher, 1997; Mehlenbacher et al., 2004) and several of these markers have been sequenced. Two of these RAPD markers, UBC152 $2_{800}$ and UBC268 ${ }_{580}$, flank the 'Gasaway' resistance gene, are easy to score and robust to amplification conditions. They are routinely used in MAS in the hazelnut breeding program at Oregon State Univ. but are absent in OSU 408.040.

In this study, we examined segregation for disease response in three progenies of selection OSU 408.040 and identified AFLP markers linked to resistance.

\section{Materials and Methods}

Plant materials. In 1997, two seedling populations were obtained from controlled crosses of the resistant selection OSU 408.040 as the pollen parent with the susceptible selections OSU 245.098 (progeny 97035) and OSU 474.013 (progeny 97036). In 
1999, a third progeny (99035) was generated by crossing OSU $665.012 \times$ OSU 408.040 (Fig. 1). For progenies 97035 and 97036 , scions were collected from 74 and 64 seedlings, respectively, in Dec. 2000, from trees growing at the Oregon State Univ. Smith Horticulture Research Farm. They were stored at $0{ }^{\circ} \mathrm{C}$ for 2 to 3 months until three trees per genotype were grafted onto C. avellana rooted layers in Spring 2001. For progeny 99035, seeds were collected in Fall 2000, stratified, sown in flats in the greenhouse when they sprouted, and grown to $\approx 20 \mathrm{~cm}$ tall. The seedlings of progeny 99035 and grafted trees of progenies 97035 and 97036 were planted in 5-L pots containing a mixture of equal volumes of peat, pumice, fine bark dust, and $9 \mathrm{~g}$ of Sierra 3- to 4-month controlled-release fertilizer $(18 \mathrm{~N}-2.6 \mathrm{P}-10.0 \mathrm{~K}$; Peters Professional, Allentown, Pa.). They were kept in the greenhouse under optimal conditions $\left(24^{\circ} \mathrm{C}\right.$ day $/ 18^{\circ} \mathrm{C}$ night $)$ until they were ready for inoculation and DNA extraction. 'Gasaway' (resistant control), 'Ennis' (susceptible control), and the parents of all three progenies were also included.

Greenhouse inoculation. Diseased twigs with mature stromata were collected from the North Willamette Research and Extension Center in Aurora, Ore., in Nov. 2000 and 2001. They were stored at $-20^{\circ} \mathrm{C}$ in polyethylene bags until they were used as inoculum. Perithecia were dissected from the stromata of infected twigs and ground with a mortar and pestle to release ascospores. The ascospore suspensions were then diluted in distilled water to $1 \times 10^{6}$ spores $/ \mathrm{mL}$. The suspensions contained in a squeeze bottle were sprayed three times to the tip(s) of one or two actively growing shoots on each tree. The sites of inoculation were indicated by tape placed two to three nodes below the apical
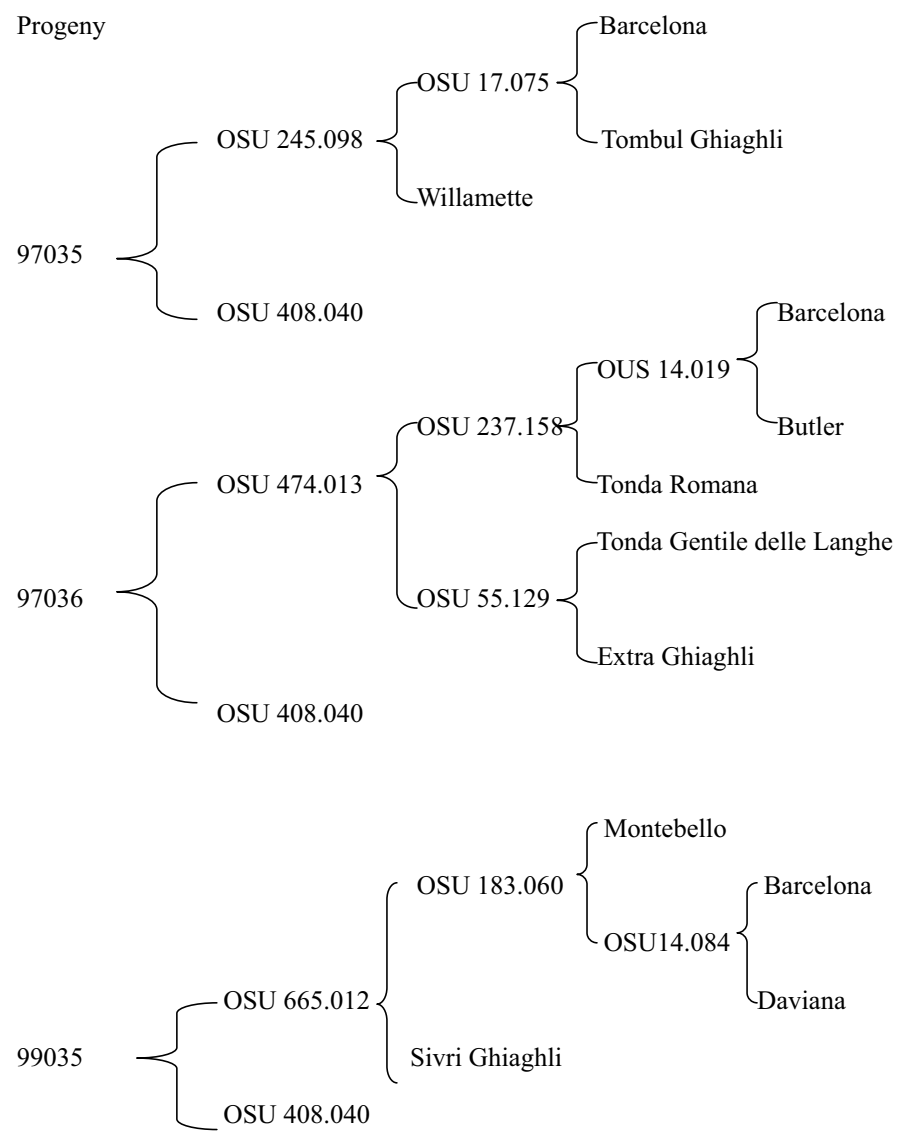

Fig. 1. Pedigrees of $C$. avellana progenies 97035, 97036, and 99035. The female parents, listed on top, are susceptible. meristem. Inoculation chambers were set up in the greenhouse, using polyvinyl chloride tubing $(1.27 \mathrm{~cm}$ diameter) placed on top of benches $(1.22 \times 0.44 \mathrm{~m})$ and covered with white $4-\mathrm{mm}$ polyethylene sheeting. A humidifier was placed in each inoculation chamber and programmed to run from 1200 to $1800 \mathrm{HR}$ and from 0000 to $0400 \mathrm{HR}$. Plants were inoculated when shoots had four to five nodes (Coyne et al., 1996). The inoculations were repeated three times at 3-d intervals. After inoculation, the trees remained in the greenhouse under optimal growing conditions for at least 6 months prior to the infection assay.

EFB RESISTANCE EVALUATION. For progenies 97035 and 97036, one greenhouse-inoculated grafted tree of each genotype was tested to score for the presence or absence of the fungus 6-8 months after inoculation using the ELISA method developed by Coyne et al. (1996) as slightly modified by Lunde et al. (2000). If the first tree showed infection, the other two trees of that genotype were transported to the North Willamette Station in Fall 2001, planted in a nursery row, and the development of cankers was noted the following winter. If the first tree showed a negative or inconclusive result, the other two trees were also tested using ELISA, and the trees remained in the greenhouse to be re-inoculated and re-assayed in 2002. A genotype was scored as susceptible if one or more of the three trees gave a positive ELISA result, and scored as resistant if all three trees remained free of infection for 2 years. For progeny 99035, each seedling was inoculated and assayed once in 2001, and then they were transported to the North Willamette Station, planted in a nursery row, and the development of cankers was visually inspected 18 months later. A genotype was scored as susceptible if the ELISA score was above the threshold and/or cankers were observed, and as resistant if the ELISA test was negative and/or no cankers were observed.

DNA EXTRACTION. Fresh young leaves of 74 seedlings of progeny 97035, 64 seedlings of progeny 97036, and the parents were collected from the field in Spring 2002. Young leaves of 48 additional seedlings of progeny 97035 were collected in Spring 2003. DNA was extracted from these leaves following the method of Lunde et al. (2000) with minor modifications, and RNA was removed by incubation at $37^{\circ} \mathrm{C}$ in the presence of RNase A(Sigma Chemical, St. Louis) for $1 \mathrm{~h}$ in a shaker, followed by extraction in 25 phenol : 24 chloroform : 1 isoamyl alcohol (Ambion, Austin, Tex.). DNA was extracted a total of four times from each seedling and stored at $-18{ }^{\circ} \mathrm{C}$ until AFLP assays. Some DNA samples were further purified using QIAprep Spin Miniprep Kit (Qiagen, Chatsworth, Calif.) to ensure successful amplification. DNA was quantified using a Hoefer DyNA Quant 2000 Fluorometer (Amersham Bioscience, San Francisco).

AFLP ANaLYSIS. Three EFB resistant seedlings, three EFB susceptible seedlings, and the two parents of progeny 97035 were used in the pre-screening process in the search for potential linked AFLP markers. In this process, the AFLP assay was performed using AFLP analysis system kit I (GIBCO BRL, Rockville, Md.) following the manufacturer's protocol. A total of 64 primer combinations (EcoRI +AAC, AAG, ACA, ACT, ACC, ACG, AGC, AGG and $M s e I+$ CAA, CAC, CAG, CAT, CTA, CTC, CTG, CTT) were used. Primer combinations that generated a band that was present in the resistant parent and all three resistant seedlings but absent in the susceptible parent and all three susceptible seedlings were investigated in a group of 30 additional seedlings. Primer pairs that generated a band that showed one recombinant in the six seedlings were also investigated further. Markers that showed $<15 \%$ recombination with resistance in these 30 seedlings were generated for the remaining seedlings in the population. After the 
initial screening, AFLP markers were generated using the protocol of Vos et al. (1995) with some modifications. Briefly, $250 \mathrm{ng}$ of genomic DNA were digested with EcoRI and MseI by incubation at $37^{\circ} \mathrm{C}$ overnight, and then held at $72{ }^{\circ} \mathrm{C}$ for $15 \mathrm{~min}$ to inactivate the enzymes. The DNA fragments were ligated with EcoRI and MseI adapters at $16^{\circ} \mathrm{C}$ for $2 \mathrm{~h}$. For pre-selective amplification, $5 \mu \mathrm{L}$ of a 10 -fold diluted ligation mixture was amplified for 20 cycles of $94^{\circ} \mathrm{C}$ for $30 \mathrm{~s}, 56^{\circ} \mathrm{C}$ for $60 \mathrm{~s}$, and $72{ }^{\circ} \mathrm{C}$ for $60 \mathrm{~s}$ using primers $E c o R I+\mathrm{A}$ and $\mathrm{MseI}+\mathrm{C}$. For selective amplification, $5 \mu \mathrm{L}$ of the combination of EcoR I+AXX and Mse I + CXX primers were mixed with $5 \mu \mathrm{L}$ of 50 -fold diluted preamplified DNA and PCR buffer. The mixture was amplified for 1 cycle of $94{ }^{\circ} \mathrm{C}$ for $30 \mathrm{~s}, 65^{\circ} \mathrm{C}$ for $30 \mathrm{~s}, 72^{\circ} \mathrm{C}$ for $60 \mathrm{~s}$, then lowering the annealing temperature $0.7^{\circ} \mathrm{C}$ each cycle for 12 cycles, and then 23 cycles of $94{ }^{\circ} \mathrm{C}$ for $30 \mathrm{~s}, 56^{\circ} \mathrm{C}$ for $30 \mathrm{~s}$, and $72{ }^{\circ} \mathrm{C}$ for $60 \mathrm{~s}$. The PCR products were checked for evidence of amplification by electrophoresis on $1 \%$ agarose gels using $5 \mu \mathrm{L}$ of the aliquot and $3 \mu \mathrm{L}$ of loading dye (15\% Ficoll 400, 0.03\% xylene cyanol FF, $0.4 \%$ orange $\mathrm{G}, 10 \mathrm{~mm}$ Tris-HCL pH 7.5, and $50 \mathrm{~mm}$ EDTA). The amplicons were mixed with an equal volume of loading dye and loaded on $6 \%$ polyacrylamide denaturing sequencing gels. Gels were run at $75 \mathrm{~W}(1600 \mathrm{~V})$ constant power for $3.5 \mathrm{~h}$ and stained with silver. The size of bands was estimated by comparison to a 100- to 1500-bp ladder (Promega, Madison, Wis.). The same AFLP analysis was carried out on progeny 97036 using primers identified in progeny 97035.

Data ANALYSIS. Segregation analysis for resistance to EFB in the three progenies was performed using the chi-square test (Table 1). A test of heterogeneity was also performed to decide whether the data from the three progenies could be pooled. AFLP markers potentially linked to the disease resistance gene were scored on 122 seedlings from progeny 97035 and 64 seedlings from progeny 97036 . Of the 122 seedlings of progeny 97035 , the EFB phenotype of 48 is unknown but these seedlings were included to more precisely determine the linkage order of the promising AFLP markers. The markers were scored as 1 indicating the presence and 0 the absence of a band. Similarly, the phenotypic data was scored as 1 for resistance and 0 for susceptibility. The data was entered in a spreadsheet, saved as a tab-delimited text file, and imported into MAPMAKER EXP 3.0 (Lander et al., 1987) using the $\mathrm{f} 2$ backcross function and default linkage criteria of $\mathrm{LOD}=3.0$ and a maximum recombination frequency of 0.25 . The most likely map order was determined using the "compare" command. The Kosambi mapping function (Kosambi, 1944) was used to convert the recombination frequency into map distances in centimorgans $(\mathrm{cM})$. The "error detection on" command tells MapMaker to perform the analysis assuming incomplete pen- etrance and a mistyping error rate of $1 \%$. Data points scored as double recombinants were reexamined by amplification of DNA template extracted from the same tree at a different time. Mistakes potentially exist in genotyping and phenotyping processes and true double recombinant events may exist, so we chose the option "error detection on." Maps were drawn using the "draw map" command of MapMaker and the resulting PS files were visualized using Ghostview software.

\section{Results}

Segregation for EFB Resistance. Disease evaluation was carried out on a total of 192 seedlings and the parents. The parent OSU 408.040 showed consistent resistance in greenhouse and field inoculations, whereas the parents OSU 245.098, OSU 474.013, and OSU 665.012 showed susceptibility to the disease. All three progenies fit the expected ratio of 1 resistant : 1 susceptible (Table 1). The heterogeneity chi-square test showed that the data were indeed homogeneous, and the pooled data also fit the expected $1: 1$ ratio, indicating control by a single locus with a dominant allele for resistance.

IDENTIFICATION OF AFLP MARKERS LINKED TO EFB RESISTANCE. Progeny 97035 was used in the search for potential AFLP markers. All 64 primer combinations successfully amplified fragments ranging from 1000 to $<100 \mathrm{bp}$ in length. Typically, 30 to 50 fragments per primer combination were produced and an average of $20 \%$ polymorphism between the resistant parent and the susceptible parent was observed.

Five markers, designated A4-265 (Fig. 2), A8-150 (Fig. 2), B2-125 (Fig. 3), C2-175 (Fig. 3), and D8-350 (Fig. 4), were closely linked in coupling to the resistance locus. All of the markers segregated in the expected 1:1 (present:absent) ratio (Table 2). The linkage analysis with a LOD score of 3.0 placed the five AFLP markers in the same linkage group as the resistance locus. The map constructed with "error detection on" spanned $13.3 \mathrm{cM}$ with markers in the order A4-265, C2-175, D8-350, A8-150, and B2-125 (Fig. 5a). Marker A8-150 co-segregated with resistance, whereas markers A4-265, C2-175 and D8-350 were located on one side of the resistance locus, and marker B2-125 was located on the other side.

To further confirm the segregation and linkage of five linked markers to the resistance locus, 64 seedlings from progeny 97036 were amplified with the same AFLP primer combinations as in the 97035 population. Three of the markers, B2-125, C2-175, and D8-350, segregated in the expected ratio of 1 present : 1 absent (Table 2). They were also found linked in coupling to the resistance locus in a similar order (Fig. 5b). Markers C2-175 and

Table 1. Segregation for resistance to eastern filbert blight in progenies of C. avellana OSU 408.040 .

\begin{tabular}{|c|c|c|c|c|c|c|}
\hline \multirow{2}{*}{ Progeny } & \multirow{2}{*}{ Parents } & \multicolumn{2}{|c|}{ Plants (no.) } & \multirow{2}{*}{$\begin{array}{l}\text { Expected } \\
\text { ratio }\end{array}$} & \multicolumn{2}{|c|}{$\chi$} \\
\hline & & Resistant & Susceptible & & Value & $\boldsymbol{P}$ \\
\hline 97035 & $245.098 \times 408.040$ & 32 & 42 & $1: 1$ & 1.35 & 0.25 \\
\hline 97036 & $474.013 \times 408.040$ & 30 & 34 & $1: 1$ & 0.25 & 0.62 \\
\hline 99035 & $665.012 \times 408.040$ & 29 & 27 & $1: 1$ & 0.07 & 0.79 \\
\hline \multicolumn{2}{|c|}{ Pooled data } & 91 & 103 & $1: 1$ & 0.74 & 0.39 \\
\hline \multicolumn{5}{|c|}{ Heterogeneity $\chi^{2}$ (degrees of freedom $=2$ ) } & 0.93 & 0.63 \\
\hline
\end{tabular}




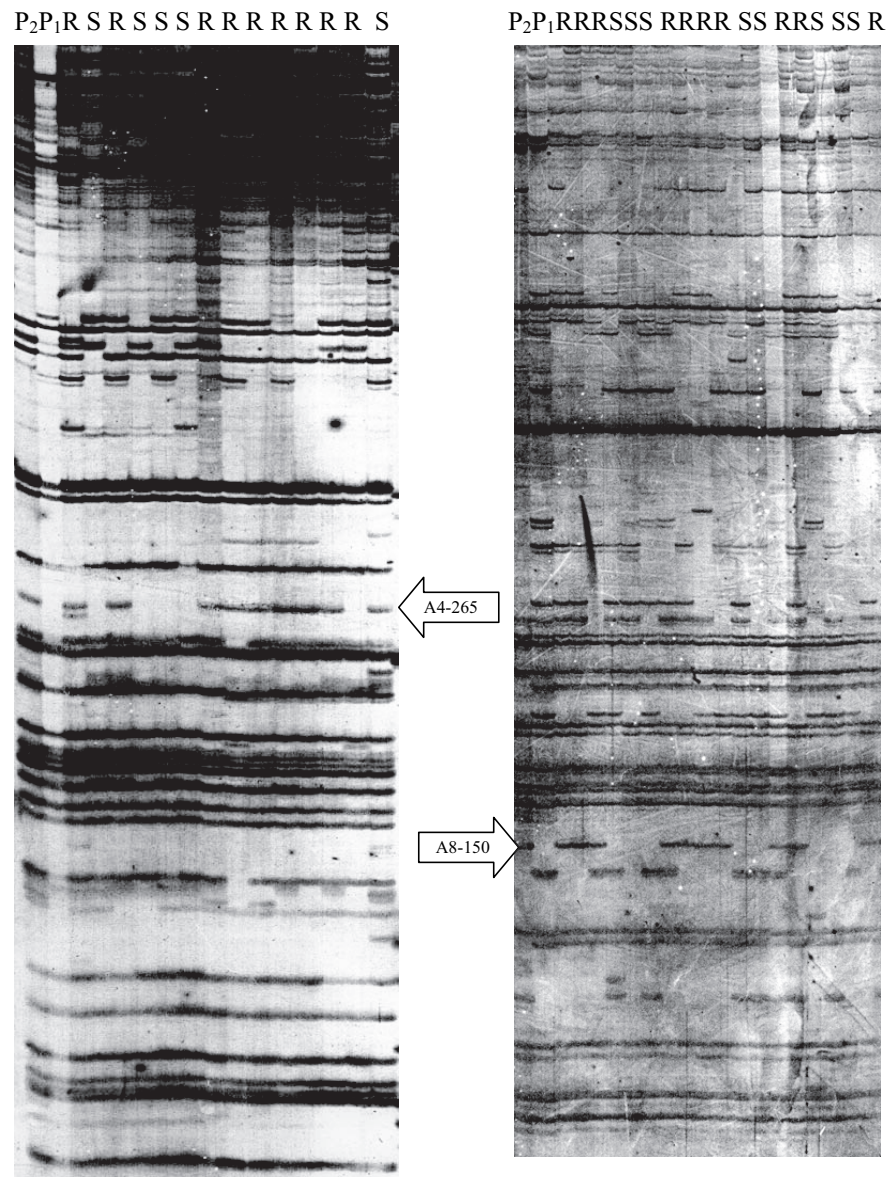

Fig. 2. Markers A4-265 and A8-150 segregate in C. avellana progeny 97035 [OSU $245.098\left(\mathrm{P}_{1}\right) \times$ OSU $408.040\left(\mathrm{P}_{2}\right)$ ]. The arrow indicates the location of the polymorphism. $\mathrm{R}=$ resistant, $\mathrm{S}=$ susceptible.

D8-350 co-segregated. Unfortunately, polymorphism was lost for A8-150 and A4-265 as a fragment of the same size and relative intensity was amplified in both parents.

\section{Discussion}

In contrast to resistance conferred by multiple minor genes, resistance conferred by a major single gene is easier to combine with high yield, kernel quality, and other desirable traits. Generally a modified backcross approach is used (Mehlenbacher, 1995). The single dominant gene from 'Gasaway' has been the major source of resistance utilized in the hazelnut breeding program at Oregon State Univ. The RAPD markers UBC $152_{800}$ and UBC $268_{580}$, which flank the resistance allele in 'Gasaway' and have been routinely used in MAS, are absent in OSU 408.040. Thus, OSU 408.040 appears to be a novel source of genetic resistance to EFB. Segregation ratios indicate that a single dominant gene from OSU 408.040 confers resistance, which means a similar approach can be used for this resistance in the breeding of new cultivars. Furthermore, the identification of this new source of resistance will be useful in the pyramiding of resistance genes and the creation of new cultivars with durable resistance to EFB.

The strategy used in identifying AFLP markers linked to the resistance locus was based on screening eight samples with a relatively large number of primer pairs to ensure that many loci could be screened for polymorphism and linkage with a limited effort. Candidate markers that were identified in this way were

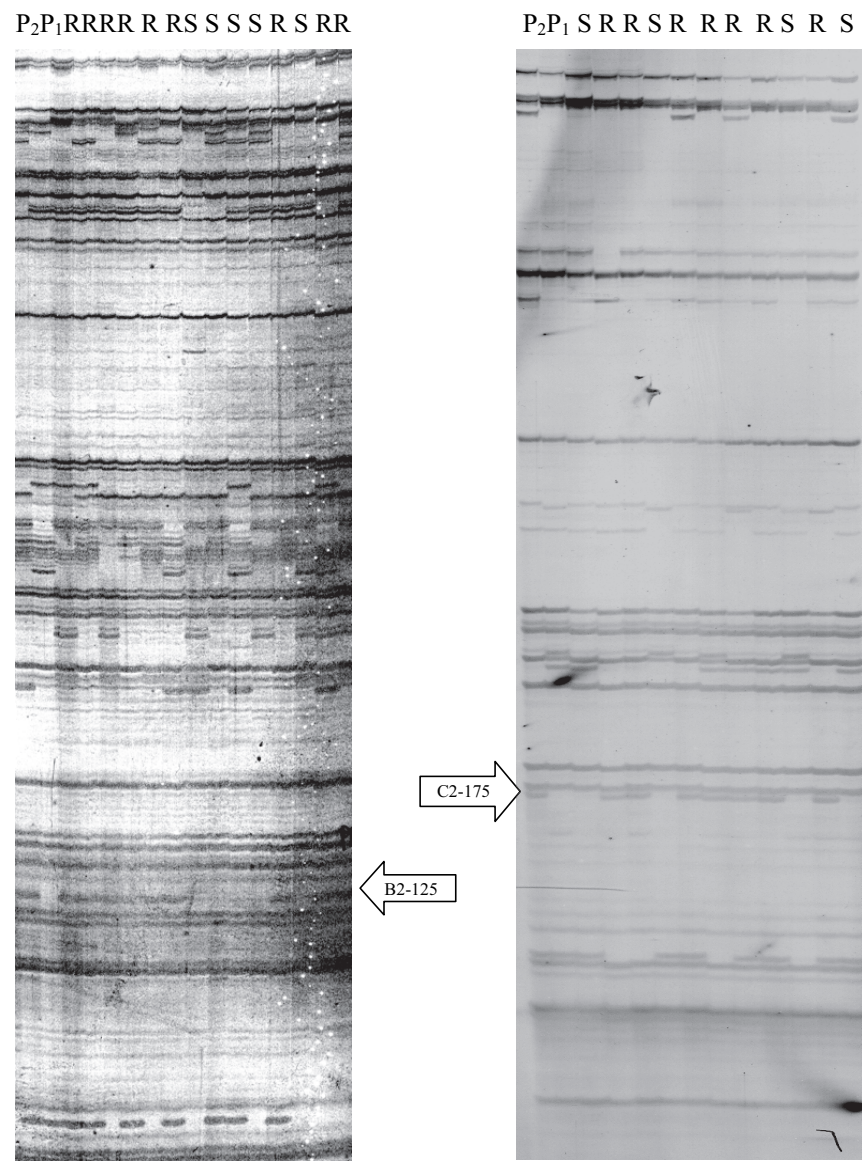

Fig. 3. Markers B2-125 and C2-175 segregate in C. avellana progeny 97035 [OSU $245.098\left(\mathrm{P}_{1}\right) \times$ OSU $408.040\left(\mathrm{P}_{2}\right)$ ]. The arrow indicates the location of the polymorphism. $\mathrm{R}=$ resistant, $\mathrm{S}=$ susceptible.

then screened on a larger number of phenotypically well-characterized samples to confirm linkage. This approach ensured that no tightly linked markers were missed but avoided further pursuit of loosely linked markers. Our strategy also overcomes two problems commonly encountered in the bulked segregant analysis (BSA) approach (Michelmore et al., 1991). With BSA, the inclusion of recombinants or incorrectly phenotyped seedlings in the bulks may prevent identification of linked markers.

MAS has been shown to be extremely powerful and efficient for traits that are simply inherited, and either difficult or expensive to evaluate by conventional methods, such as many types of disease resistance (Dreher et al., 2002; Dudley, 1993; Kelly, 1995; Lande and Thompson, 1990; Luby and Shaw, 2001; Mehlenbacher, 1995; Melchinger, 1990; Young, 1999). These AFLP markers, especially those tightly linked $(<5 \mathrm{cM})$ (Mohan et al., 1997; Tanksley, 1983) to the resistance locus in OSU 408.040, may be useful in a MAS program provided that they are absent in the susceptible parents. AFLP markers will be more useful in a MAS program if they are applicable across a range of genetic backgrounds (Kelly, 1995). The marker linked closest to the resistance locus, A8-150, could only be scored in the OSU 245.098 $\times$ OSU 408.040 and was not useful in the second progeny. The marker B2-125 appears to be a promising one as it could be scored in both progenies. The practical application of large-scale MAS in applied plant breeding programs requires high-throughput, cost-effective, reliable and easy to score marker assays. Although the AFLP technique is reliable, it is difficult to employ directly 


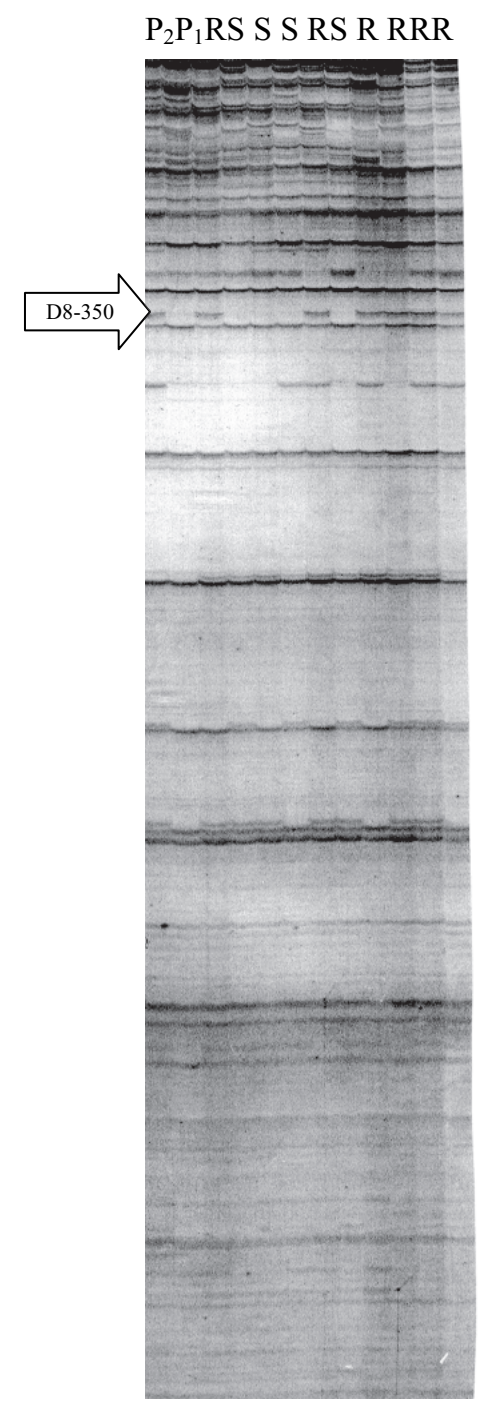

Fig. 4. Marker D8-350 segregates in $C$. avellana progeny 97035 [OSU 245.098 $\left(\mathrm{P}_{1}\right) \times$ OSU $\left.408.040\left(\mathrm{P}_{2}\right)\right]$. The arrow indicates the location of the polymorphism. $\mathrm{R}=$ resistant, $\mathrm{S}=$ susceptible.

Table 2. AFLP markers and their segregation in C. avellana progenies 97035 (122 seedlings) and 97036 (64 seedlings).

\begin{tabular}{|c|c|c|c|c|c|c|}
\hline \multirow[b]{2}{*}{ Parents } & \multirow[b]{2}{*}{$\begin{array}{c}\text { Primer } \\
\text { combinations }\end{array}$} & \multirow{2}{*}{$\begin{array}{c}\text { AFLP } \\
\text { marker } \\
\text { designation }\end{array}$} & \multirow{2}{*}{\begin{tabular}{|c} 
Observed \\
frequency \\
(present: \\
absent)
\end{tabular}} & \multirow[b]{2}{*}{$\begin{array}{l}\text { Expected } \\
\text { ratio }\end{array}$} & \multicolumn{2}{|c|}{$\chi^{2}$} \\
\hline & & & & & Value & $P$ \\
\hline \multirow{5}{*}{$245.098 \times 408.040$} & EAAC/MCAT & A4-265 & $64: 58$ & $1: 1$ & 0.30 & 0.59 \\
\hline & EAAC/MCTT & A8-150 & $61: 61$ & $1: 1$ & 0.00 & 1.00 \\
\hline & EAAG/MCAC & B2-125 & $62: 60$ & $1: 1$ & 0.03 & 0.86 \\
\hline & EACA/MCAC & C2-175 & $62: 60$ & $1: 1$ & 0.03 & 0.86 \\
\hline & EACT/MCTT & D8-350 & $61: 61$ & $1: 1$ & 0.00 & 1.00 \\
\hline \multirow{3}{*}{$474.013 \times 408.040$} & EAAG/MCAC & B2-125 & $28: 36$ & $1: 1$ & 1.00 & 0.32 \\
\hline & EACA/MCAC & $\mathrm{C} 2-175$ & $32: 32$ & $1: 1$ & 0.00 & 1.00 \\
\hline & EACT/MCTT & D8-350 & $32: 32$ & $1: 1$ & 0.00 & 1.00 \\
\hline
\end{tabular}

A

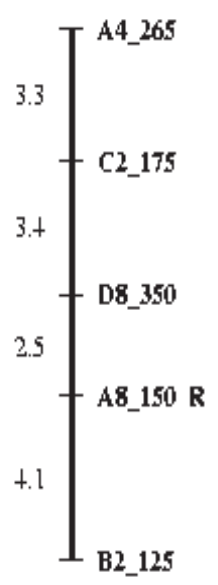

B

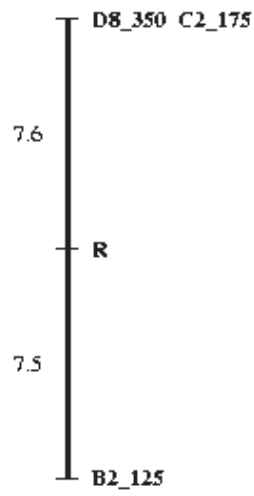

Fig. 5. Most likely map orders of AFLP markers and the resistance locus in C. avellana for (A) progeny 97035 and (B) progeny 97036 with "error detection on." because it is complicated, technologically demanding, and costly. Further studies should be carried out to convert the AFLP markers identified in this study to sequence-characterized amplified regions (Paran and Michelmore, 1993) or to cleaved amplified polymorphic sequence markers (Konieczny and Ausubel, 1993) for their application in a MAS program.

\section{Literature Cited}

Cameron, H.R. 1976. Eastern filbert blight established in the Pacific Northwest. Plant Dis. Rptr. 60:737-740.

Coyne, C.J., S.A. Mehlenbacher, R.O. Hampton, J.N. Pinkerton, and K.B. Johnson. 1996. Use of ELISA to rapidly screen hazelnut for resistance to eastern filbert blight. Plant Dis. 80:1327-1330.

Davis, J.W. and S.A. Mehlenbacher. 1997. Identification of RAPD markers linked to eastern filbert blight resistance in hazelnut. Acta Hort. 445:553-556.

Dreher, K., M. Morris, M. Khairallah, M. Ribaut, P. Shivaji, S. Ganesan, S. Pandey, G. Srinivasan, R.E. Evenson, V. Santaniello, and D. Zilberman. 2002. Is marker-assisted selection cost-effective compared with conventional plant breeding methods? The case of quality protein maize. Econ. Social Issues Agr. Biotechnol. 15:203-236.
Dudley, J.W. 1993. Molecular markers in plant improvement: manipulation of genes affecting quantitative traits. Crop Sci. 33:660-668.

Food and Agriculture Organization of the United Nations. 2003. FAO Production Yrbk. United Nations, New York.

Kelly, J.D. 1995. Use of random amplified polymorphic DNA markers in breeding for major gene resistance to plant pathogens. HortScience 30:461-465.

Konieczny, A. and F.M. Ausuble. 1993. A procedure for mapping Arabidopsis mutations using co-dominant ecotype-specific PCR-based markers. Plant J. 4:403-410.

Kosambi, D.D. 1944. The estimation of map distances from recombination values. Ann. Eugenics 12:172-175.

Lande, R. and R. Thompson. 1990. Efficiency of marker-assisted selection in the improvement of quantitative traits. Genetics 124:743-756.

Lander, E.S., P. Green, J. Abrahamson, A. Barlow, M.J. Daly, S.E. Lincoln, and L. Newburg. 1987. MAPMAKER: An interactive computer package for constructing primary genetic linkage maps of experimental and natural populations. Genomics 1:174-181.

Luby, J.J. and D.V. Shaw. 2001. Does marker-assisted selection make dollars and sense in a fruit breeding program? HortScience 36:872-879.

Lunde, C.F., S.A. Mehlenbacher, and D.C. Smith. 2000. Survey of 
hazelnut cultivars for response to eastern filbert blight inoculation. HortScience 35:729-731.

Mehlenbacher, S. 1994. Genetic improvement of the hazelnut. Acta Hort. 351:23-38.

Mehlenbacher, S. 1995. Classical and molecular approaches to breeding fruit and nut crops for disease resistance. HortScience 30:466-477.

Mehlenbacher, S.A., R.N. Brown, J.W. Davis, H. Chen, N.V. Bassil, D.C. Smith, T.L. Kubisiak. 2004. RAPD markers linked to eastern filbert blight resistance in Corylus avellana. Theor. Appl. Genet. 108:651-656.

Mehlenbacher, S.A., M.M. Thompson, and H.R. Cameron. 1991. Occurrence and inheritance of resistance to eastern filbert blight in 'Gasaway' hazelnut. HortScience 26:410-411.

Melchinger, A.E. 1990. Use of molecular markers in breeding for oligogenic disease resistance. Plant Breeding 104:1-19.

Michelmore, R.W., I. Paran, and R.V. Kesseli. 1991. Identification of markers linked to disease-resistance genes by bulked segregant analysis: A rapid method to detect markers in specific genomic regions by using segregating populations. Proc. Natl. Acad. Sci. USA 88:9829-9832.
Mohan, M., S. Nair, A. Bhagwat, T.G. Krishna, M. Yano, C.R. Bhatia, and T. Sasaki. 1997. Genome mapping, molecular markers and markerassisted selection in crop plants. Mol. Breeding 3:87-103.

Paran, I. and R.W. Michelmore. 1993. Development of reliable PCRbased markers linked to downy mildew resistance genes in lettuce. Theor. Appl. Genet. 85:985-993.

Pinkerton, J.N., K.B. Johnson, S.A. Mehlenbacher, and J.W. Pscheidt. 1993. Susceptibility of European hazelnut clones to eastern filbert blight. Plant Dis. 77:261-266.

Tanksley, S.D. 1983. Molecular markers in plant breeding. Plant Mol. Biol. Reporter 1:3-8.

Vos, P., R. Hogers, M. Bleeker, M. Reijans, T. van de Lee, M. Hornes, A. Frijters, J. Pot, J. Peleman, M. Kuiper, and M. Zabeau. 1995. AFLP: A new technique for DNA fingerprinting. Nucleic Acids Res. 23:4407-4414.

Weschcke, C. 1954. Growing nuts in the north. Webb, St. Paul, Minn. p. 24-38.

Young, N.D. 1999. A cautiously optimistic vision for marker-assisted breeding. Mol. Breeding 5:505-510. 